Canadian Journal of Higher Education

Revue canadienne d'enseignement supérieur

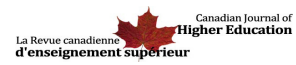

\title{
Understanding Campus Culture and Student Coping Strategies for Mental Health Issues in Five Canadian Colleges and Universities
}

\author{
Dimitris Giamos, Alex Young Soo Lee, Amanda Suleiman, Heather Stuart et \\ Shu-Ping Chen
}

Volume 47, numéro 3, 2017

URI : https://id.erudit.org/iderudit/1043242ar

DOI : https://doi.org/10.7202/1043242ar

Aller au sommaire du numéro

Éditeur(s)

Canadian Society for the Study of Higher Education

ISSN

2293-6602 (numérique)

Découvrir la revue

\section{Citer cet article}

Giamos, D., Lee, A., Suleiman, A., Stuart, H. \& Chen, S.-P. (2017). Understanding Campus Culture and Student Coping Strategies for Mental Health Issues in Five Canadian Colleges and Universities. Canadian Journal of Higher Education / Revue canadienne d'enseignement supérieur, 47(3), 136-151. https://doi.org/10.7202/1043242ar

\section{Résumé de l'article}

Cette étude vise à mieux comprendre la culture de la santé mentale au sein de différents campus ainsi que les stratégies d'adaptation adoptées par les étudiants, puis à relever les besoins des étudiants et les lacunes quant à l'offre de services en santé mentale des institutions postsecondaires. Nous avons eu recours à la méthode " videovoice " dans le but d'identifier et de documenter les problèmes de santé mentale, puis de plaider en faveur d'un changement. Quarante-et-une entrevues ont été réalisées auprès d'intervenants sur les campus de cinq différentes universités. De ces entrevues, cinq thèmes liés à la santé mentale ont émergé, soit la stigmatisation liée à la santé mentale, la culture des campus, la disponibilité des services en santé mentale et les obstacles de l'offre de tels services, les accommodements offerts par les campus, et les stratégies d'adaptation des étudiants. Nous avons élaboré un documentaire qui plaide en faveur de la santé mentale. Nous concluons que, bien que les campus canadiens sensibilisent leurs étudiants à ce sujet, il y a absence de soutien en termes d'infrastructure pour la santé mentale sur les campus. En effet, l'accès des ressources en santé mentale doit particulièrement être amélioré sur les campus.
Copyright (c) Dimitris Giamos, Alex Young Soo Lee, Amanda Suleiman, Heather Stuart, Shu-Ping Chen, 2017

Attribution-NonCommercial-No Derivative Works 2.5 Canada
Ce document est protégé par la loi sur le droit d'auteur. L’utilisation des services d'Érudit (y compris la reproduction) est assujettie à sa politique d'utilisation que vous pouvez consulter en ligne.

https://apropos.erudit.org/fr/usagers/politique-dutilisation/ 


\title{
Understanding Campus Culture and Student Coping Strategies for Mental Health Issues in Five Canadian Colleges and Universities
}

Dimitris Giamos

Concordia University

Alex Young Soo Lee

McMaster University

Amanda Suleiman

McMaster University

Heather Stuart

Queen's University

Shu-Ping Chen

University of Alberta

\begin{abstract}
This study aimed to better understand campus mental health culture and student mental health coping strategies, and to identify the mental health needs of students as well as gaps in mental health services within postsecondary education. A videovoice method was used to identify and document health-related issues and advocate for change. Forty-one interviews were conducted with campus stakeholders at five universities. Five themes involving mental health emerged from the campus interviews: the stigma of mental illness; campus culture related to mental health; mental health services available and barriers to mental health services on campus; accommodations for students' mental health needs; and student mental health coping strategies. A documentary was
\end{abstract}


developed to advocate for better mental health. We conclude that although Canadian campuses are raising awareness about mental health issues, there is not enough mental health infrastructure support on campuses; in particular, accessibility to campus mental health resources needs improvement.

\section{Résumé}

Cette étude vise à mieux comprendre la culture de la santé mentale au sein de différents campus ainsi que les stratégies d'adaptation adoptées par les étudiants, puis à relever les besoins des étudiants et les lacunes quant à l'offre de services en santé mentale des institutions postsecondaires. Nous avons eu recours à la méthode « videovoice » dans le but d'identifier et de documenter les problèmes de santé mentale, puis de plaider en faveur d'un changement. Quarante-etune entrevues ont été réalisées auprès d'intervenants sur les campus de cinq différentes universités. De ces entrevues, cinq thèmes liés à la santé mentale ont émergé, soit la stigmatisation liée à la santé mentale, la culture des campus, la disponibilitédes servicesen santémentale etlesobstacles del'offre detelsservices, les accommodements offerts par les campus, et les stratégies d'adaptation des étudiants. Nous avons élaboré un documentaire qui plaide en faveur de la santé mentale. Nous concluons que, bien que les campus canadiens sensibilisent leurs étudiants à ce sujet, il y a absence de soutien en termes d'infrastructure pour la santé mentale sur les campus. En effet, l'accès des ressources en santé mentale doit particulièrement être amélioré sur les campus.

College and university students are at high risk for developing mental health issues, conditions that may affect their ability to think and feel. Severe mental health issues may affect students' ability to perform daily functions and interact with other members of the community. According to a General Health Questionnaire (Adlaf, Demers, \& Gliksman, 2005), nearly one-third of Canadian undergraduate university students reported experiencing elevated psychological distress. In 2011, the mental illness-associated suicide rate accounted for $24 \%$ of all deaths among $15^{-24}$-year-olds, amounting to 4,000 youths (Statistics Canada, 2011). As indicated by the 2004 Canadian Campus Survey, $42 \%$ of university students were more likely than $17 \%$ of non-university students to report symptoms of mental illness (Adlaf, Demers, \& Gliksman, 2005). Furthermore, 2009 prevalence data from six Ontario postsecondary institutions estimated that more than $80 \%$ of the students felt overwhelmed or exhausted and that $4 \%$ of the students had a psychiatric condition. The epidemiological data indicated that mental health problems are highly prevalent among postsecondary students; however, only $15.4 \%$ of the students reported they had been treated by a professional for one or more mental health problems (ACHA-NCHA II, 2009).

Inadequate education regarding mental health coping strategies, and the perception of stigma accorded to mental illnesses, are large problems among university students (Mahmoud, Staten, Hall, \& Lennie, 2012). The transition from high school to a postsecondary institution is a life-changing experience that often takes place without adequate family or institutional support (Terenzini et al., 1994). Peer-pressure, perceived stigma, lack of understanding of campus counselling services, and a negative previous experience are barriers to accessing mental health services and supports at a postsecondary institu- 
tion (Bray \& Born, 2004). When students fail to reach expectations they have set out for themselves in the new academic environment, disappointment, anxiety, and depression may follow (Eisenberg, Downs, Golberstein, \& Zivin, 2009; Mowbray et al., 2006; Corrigan, Markowitz, Watson, Rowan, \& Kubiak, 2003). Such negative feelings can hinder a student's willingness to seek support (Corrigan, Edwards, Green, Diwan, \& Penn, 2001).

According to the literature, the stigma of mental illness on campus can force students to stay silent about their hardships. Eisenberg, Downs, Golberstein, and Zivin (2009) examined 5,555 students from 13 universities and found that the stigma of mental illness perceived from peers and others was more prevalent than the personal (self) stigma. However, personal stigma was more prevalent than peer stigma among students who were male, young, Asian, religious, or from a poor family and was negatively correlated with the likelihood of seeking professional support for mental health problems. "Unstable" or "dangerous" stereotypes can account for much of the stigma attached to mental illness.

In response to this situation, changes at both national and provincial levels have been made to postsecondary institutions to accommodate the mental health needs of students. For example, the Canadian Association of College and University Student Services (CACUSS) has developed a framework wherein postsecondary students with mental health concerns can be educated regarding coping and crisis management skills at accessible community mental health and counselling services (CACUSS, 2013). Some provinces are taking independent action. For example, the Ontario government in 2014 pledged $\$ 12$ million over two years to support the province's Mental Health Innovation Fund and other initiatives that advocate for student-led projects to raise awareness about seeking appropriate mental health support (Perez, Murphy, \& Gill, 2014). The Mental Health Commission of Canada has also set an agenda for transforming and building capacity in campus mental health services.

While progress is evident, issues associated with mental illness remain inadequately addressed. For example, a study published in 2014 pointed out that although almost all of Alberta's institutions contained counselling centres, there was a lack of long-term therapy available for students, and students were rarely referred to outside resources. The findings suggested a need for a more systematic mental health approach in which mental health services and initiatives could be effectively and efficiently delivered to students in need of support (Heck et al., 2014).

This project builds on Unleash the Noise 2013, a national student mental health summit held in Toronto-an entirely student-inspired, student-organized, and student-led event to promote campus mental health (Jack.org, 2013). By engaging students and focusing on their strengths as young people, Unleash the Noise inspired and empowered students to change the way they think about mental health. This conference raised awareness of a need for collaborative research examining the mental health culture in postsecondary institutions. The present project, titled Unleash the Academia, was the product of and conducted under the auspices of Jack.org, the Opening Minds Initiative of the Mental Health Commission of Canada, and the Bell Canada Mental Health and Anti-Stigma Research Chair at Queen's University.

The current project brought together five university student delegates from two Canadian provinces to examine mental health in campus cultures and student coping strategies for mental health problems from the perspective of the students themselves. A par- 
ticipatory needs assessment using the videovoice method explored the perspectives of campus mental health culture through a student lens, created a powerful student voice, and suggested strategies for mental health promotion in the campuses studied, with implications for other Canadian campuses.

\section{Background}

Videovoice is a medium used for health promotion. Participants use videography to identify and document health-related issues and advocate for change (Catalani et al., 2012; Warren, Knight, Holl, \& Gupta, 2014). Similar visual methods, such as participatory video or video storytelling, have emerged to engage people in health promotion (Gubrium \& Turner, 2011; Lunch \& Lunch, 2006). For example, Catalani et al. (2012) conducted a videovoice project in post-Katrina New Orleans, aiming to empower community residents by documenting their concerns and communicating their needs. The distribution of the resulting film helped mobilize the community for action on three issues-affordable housing, education, and economic development (Catalani et al., 2012). Wexler et al. (2013) conducted a video storytelling project for youths to reflect on and represent their lives. They identified positive aspects of youths' lives in the videos, which now serve as digital "hope kits" for youth suicide prevention (Wexler, Gubrium, Griffin, \& DiFulvio, 2013). This project demonstrated the use of the videovoice method to promote positive mental health.

We used a videovoice technique within a mental health promotion framework that emphasizes power and resilience (CAMH, n.d.). This framework acknowledges that students themselves are the best ones to explore their culture and articulate their needs. We also recognized that students have the capacity to cope with life, which is one of the major factors in resilience. Applying the two concepts together in the videovoice process, we empowered students to build on their existing capacities to increase power and control, to assess their mental health culture, and to explore positive coping strategies for mental health promotion.

\section{Methods}

We used the videovoice technique to document and record student perspectives, the mental health culture of campuses, and student mental health issues. Campus stakeholders were videotaped as they reflected on their personal experiences and voiced their perspectives and needs regarding the mental health services in their postsecondary institutions. The research involved seven processes (see Figure 1):

\section{Process 1 - Research Team Building}

The research team included two principal investigators (two university faculty members who facilitated and supervised the project) and five undergraduate students from college and university campuses in Canada who served as lead co-investigators for their campuses. We recruited the lead co-investigators during the Unleash the Noise National Student Mental Health Summit. Eight students were accepted for the positions, but three subsequently dropped out. The final team included five lead co-investigators, four from Ontario campuses and one from a Québec campus. They were paid a small amount of the research stipend. 


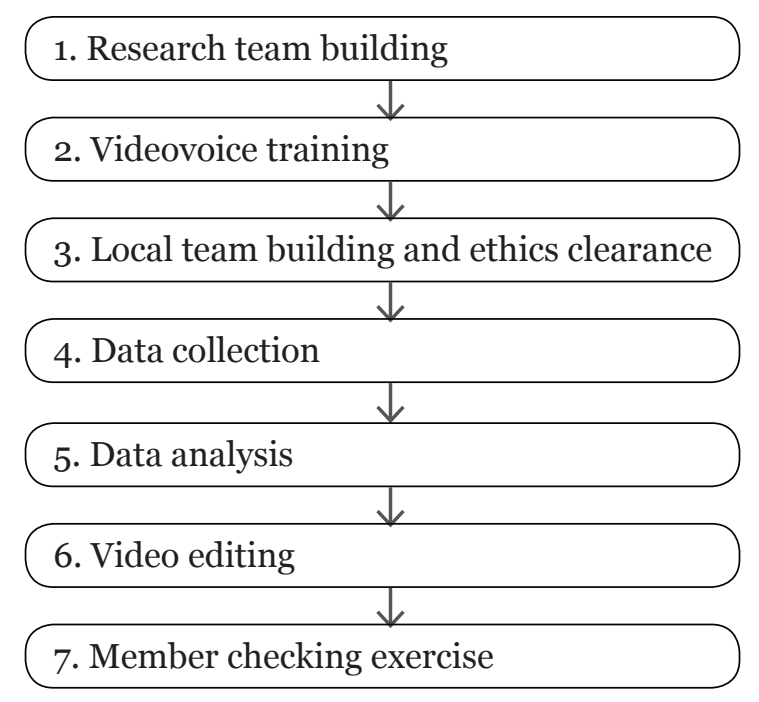

Figure 1. The research process

\section{Process 2-Videovoice training}

The five lead co-investigators received one day of videovoice training from the two principal investigators. The training included a three-hour lecture in the morning, discussing knowledge and skills required to implement the videovoice method and community-based participatory research, and a three-hour open group discussion that explored how they would document mental health issues on their campuses. As part of the participatory process, they were empowered to decide on the topics, content, length, and operational details of their videography. They also discussed ways to recruit local student researchers and create effective research teams. Following the training, we held a one-hour webinar with a videographer who taught the lead co-investigators critical skills for producing videos.

\section{Process 3-Local Research Team Building and Ethics Clearance}

The lead co-investigators recruited additional volunteer student researchers from their local campuses to help with the data collection, as they deemed appropriate. The recruitment strategies included reaching out to students who were interested in mental health topics, contacting school health services for resource referrals, and distributing advertisements in schools. With the support of the principal investigators, the lead coinvestigators were also authorized to obtain ethics approval from their universities and colleges. In one case, the ethics process proved impossible to negotiate for a student without an in-house principal investigator, so the student had to drop out of the project.

\section{Process 4-Data Collection}

Unique to this study was the fact that the student lead co-investigators, with a vested interest in student mental health, conducted the majority of data collection, including recruiting participants and conducting interviews. Each campus team produced video clips designed to cover two topics: (1) the campus culture related to mental health, mental wellness, and mental illness; and (2) students' coping strategies with mental health issues. Over a four-month period, they used videovoice techniques (such as recoding first-person 
accounts and interviews) to produce their video clips. Participants who were interviewed and videotaped at each campus were informed that the videos were part of a research project. In the informed consent process, participants agreed to release their videography to the research team and to have it used in mental health promotional materials.

Next, the lead co-investigators contextualized their video information by explaining how their video clips were related to larger mental health study issues. As part of the data collection process, they included a brief reflection on their research experiences and what they had observed during the research process.

\section{Process 5-Data Analysis}

The individual video clips and the resulting commentaries formed the basis of the qualitative analysis. The interview videos were transcribed verbatim. Qualitative data analysis involves two stages: contextualizing and codifying (Wang \& Burris, 1997).

Contextualizing: After the co-investigators interpreted the videography that most accurately reflected their campus culture and needs, the principal investigators and the co-investigators engaged in critical discussion to understand the stories and contexts of the videos.

Codifying: One principal investigator read all transcripts, coded the transcripts line by line, wrote a preliminary code label on the edge of a record, and then made a second pass through the codes to organize sets of concepts. Finally, the principal investigators and the co-investigators worked together to identify issues and themes in the data. A total of five themes emerged.

\section{Process 6-Video Editing}

A professional videographer edited the documentary based on the five themes found in the qualitative data. A three-minute clip was developed for each theme and included the lead co-investigator's commentary.

\section{Process 7-Member Checking Exercise}

The final themes and documentary were sent back to the participants for a member checking exercise. We revised the documentary accordingly. Once complete, the co-investigators were encouraged to organize a public screening of the documentary at their respective campuses.

\section{Videos}

\section{Results}

All interviews were videotaped to allow for subsequent transcription and to enable inclusion in the study documentary. The videos vary slightly in appearance, as they were filmed in multiple cities by different researchers using different cameras. However, general guidelines were followed to ensure consistency between interviews. The videos focused on the participant being interviewed, with their upper body within the frame; interviewers asked questions off camera. Participants often faced the interviewers off camera and so did not look directly at the camera. Videos ranged in length based on the content the participant shared during the interview. 


\section{Participants}

Forty-one interviews were conducted with participants from five Canadian postsecondary campuses in Ontario and Québec. Out of the 41 participants, 11 (26.8\%) were male and 30 (73.1\%) were female. Participants were students from a variety of disciplines, and 11 participants were professors or staff members at the universities (see Table 1).

Table 1. Participant Profile

\begin{tabular}{lcccccc}
\hline & $\begin{array}{c}\text { School 1 } \\
\text { (Québec) }\end{array}$ & $\begin{array}{c}\text { School 2 } \\
\text { (Ontario) }\end{array}$ & $\begin{array}{c}\text { School 3 } \\
\text { (Ontario) }\end{array}$ & $\begin{array}{c}\text { School 4 } \\
\text { (Ontario) }\end{array}$ & $\begin{array}{c}\text { School 5 } \\
\text { (Ontario) }\end{array}$ & Total \\
\hline $\begin{array}{l}\text { Total interviewees } \\
\text { Gender }\end{array}$ & 7 & 13 & 2 & 12 & 7 & 41 \\
$\quad$ Female & 6 & 9 & 1 & 9 & 5 & 30 \\
$\quad$ Male & 1 & 4 & 1 & 3 & 2 & 11 \\
Role & 7 & 6 & - & 12 & 5 & 30 \\
$\quad$ Student & - & 7 & 2 & - & 2 & 11 \\
$\quad$ Staff & & & & & & \\
\hline
\end{tabular}

Five central themes emerged in the interviews: (1) the stigma of mental illness, (2) campus culture related to mental health, (3) the availability of mental health services and barriers to mental health services on campus, (4) campus accommodations of students' mental health needs, and (5) student mental health coping strategies. Most interview participants were enthusiastic about being able to talk about student mental health; as one person explained: "I'm so happy that there is finally a conversation being started ... not just at our campus, but I'm finding that it's expanding to other campuses as well" (S4P2).

\section{The Stigma of Mental Illness}

There were mixed responses regarding the current status of stigma associated with mental health issues on Canadian postsecondary campuses. Some interviewees felt that stigma related to mental health problems remains prevalent on campus; one participant noted, "I definitely do see stigma around mental health on campus, where students are still hesitant to say they're going to see counsellors" (S2P2). Others felt that there was little stigma attached to seeking support for mental health issues: "No, I don't feel stigmatized. I feel that most faculty [members] here are very accepting of people with mental health problems. So I feel very comfortable" ( $\mathrm{S} 1 \mathrm{P} 1)$. Others testified that the stigma regarding mental illness on campuses was part of a larger culture of mental illness stigma in communities. One participant observed, "I think [the university] is a part of the world, and there is stigma surrounding mental health everywhere, so if there's stigma elsewhere, there is stigma at [the university]" $\left(\mathrm{S}_{5} \mathrm{P} 1\right)$.

A major cause of the stigma associated with mental problems was considered to be the emphasis universities place on achievement and students' academic success, which may make it difficult for people to seek support and resources when they are struggling with mental or emotional problems. A residence outreach counsellor commented: 
There is a very big, high-level value placed on achievement and accomplishmentsand I think this has made it difficult for some students to really express that they are having difficulties ... whether mental health, whether it is studying, whether it is academic, whether it is social connection ... so I think that contributes a bit in terms of stigma. $\left(\mathrm{S}_{3} \mathrm{P} 1\right)$

Despite differences in opinion about the prevalence of stigma regarding mental illness, there was a consensus that more needs to be done to reduce the power of stigma. One participant suggested that simply talking about it would make it less of a taboo subject:

I think the best way to eliminate stigma is to get people to talk about it, so for those individuals who have no experience with mental illness or don't know anybody with mental illness can get a better understanding of it by knowing that some of their friends or people they perceive as completely normal and successful individuals might be struggling with mental illnesses as well, and then they have people who they could ask questions to and get a better understanding of it. (S2P1)

\section{Campus Culture Related to Mental Health}

Participants generally rated campus culture surrounding mental health as positive and improving over time, but with continued work remaining. As one participant described:

I think having been here [on campus] for five years, it's definitely become something, mental health is becoming something a lot more discussed ... so now we have student groups that are really focused towards finding ways to support students with mental health. It's become . . . one of those buzzwords now, now that people are aware, they know it exists within university campuses. (S2P3)

Another participant commented: "I think the culture has been changing. There are more and more students who understand the term mental health" ( $\left.\mathrm{S}_{5} \mathrm{P} 6\right)$.

Positive initiatives on campus. When discussing campus culture surrounding mental health, many participants brought up examples of campaigns or events at the university meant to increase awareness or reduce mental illness stigma. One participant explained: "They [the university] definitely put effort into doing it . . . they had a day where they hand out flyers and test out people's stress levels, and give them different ways of coping with it" ( $\left.\mathrm{S}_{1} \mathrm{P}_{3}\right)$. Another participant-a residence don-discussed wellness programs for new students:

Five different workshops on five different topics, like eating well, mental health, exercise, academics . . . I was surprised . . . because it opened up those students who were attending the workshop, and I did not know that there were so many people going through the same things that I have been through as well. ( $\left.\mathrm{S}_{4} \mathrm{P}_{5}\right)$

Participants agreed that these types of programs are a necessary, but not all-encompassing, step toward changing campus culture: One student observed:

I think there are a lot of positive campaigns happening around mental health ... it's a really great beginning ... I think we need to see more institutional support in terms of the way that the university structure creates mental health for students. (S4P4) 


\section{Mental Health Services Available and Barriers to Mental Health Services on Campus}

While participants rated mental health services on campus as adequate overall, there was a consistent discussion of long wait times being a major barrier for students to access services in a timely and meaningful way. One student explained:

Although I do think the counsellors here are very helpful, I find that I have a hard time booking an appointment with them ... so if you're really stressed out, and you really need someone to talk to, sometimes you might have a hard time getting in touch with a counsellor, so that might be a bit of an issue. ( $\left.\mathrm{S}_{1} \mathrm{P} 1\right)$

Some students suggested that peer support was an alternative and/or supplement to traditional university counselling services, as well as a way to mediate extended wait times. One student commented:

So you end up waiting a long time in between appointments, which was really hard for me... [the university] has peer support where you can just walk in and get oneon-one peer support with someone, which is really great. ( $\left.\mathrm{S}_{4} \mathrm{P}_{3}\right)$

There were also barriers to accessing services because students often did not know that services existed or that the available services would apply to their specific situation. Another participant explained: "I didn't know that there's disability services at [the university] for mental health issues, and maybe that's my own sense of stigma ... I thought they were more for physical [issues]" ( $\left.\mathrm{S}_{5} \mathrm{P}_{5}\right)$. The physical space provided for counselling and support services also proved to be an important factor in either eliminating or creating a barrier to mental healthcare support. According to one student,

[located] at the end of the hallway in the basement ... sometimes it almost feels like a walk of shame to go down there [to the campus wellness centre], and it's not a really conducive thing for getting students to go visit them. (S2P1)

Another issue brought up by participants was the necessity for cultural sensitivity and the unique needs of international students. One participant noted, "I must emphasize that there is room for considerable improvement-there is not enough support and resources for international students, and staff are not adequately trained to assist international students" ( $\left.\mathrm{S}_{5} \mathrm{P}_{4}\right)$.

\section{Campus Accommodations for Students' Mental Health Needs}

Some participants shared their experiences of obtaining and using specific mental health accommodations in collaboration with their universities to support their learning needs. One type of campus accommodation was a special use of certain facilities or technology on campus, as one student explained:

I also have access to audio-visual software, so I can convert my readings from text to audio ... . and download to my iPod ... like I'm on the bus, I'm not listening to music, I'm actually going through my reading. $\left(\mathrm{S}_{5} \mathrm{P}_{4}\right)$ 
Another common campus accommodation included flexibility and special arrangements for writing exams, which one participant found quite helpful:

You can actually get accommodations, if you have the paperwork you did with your doctor, it's really easy. I have 50\% more time for all of my exams, access to a computer, access to auto-correct, and it really, really, really, really [sic] helped me. And it's really available, but you need to know where to go, though. (S1P8)

While students tended to find these types of accommodations helpful for their learning and well-being, there were barriers to access, including the application process, the eligibility criteria, and knowing that the accommodations existed at all. There was some discussion about the necessity of a diagnosis in order to be seen as truly deserving of supports-for example:

I know there are programs that are in place if you have ADHD; with a note saying that it's legitimate, you will get extra time on exams and for that reason, I do think that it is accepting. But that being said, if you have more personal problems . . . I don't think teachers will be that accepting. ( $\left.\mathrm{S}_{1} \mathrm{P}_{5}\right)$

\section{Student Mental Health Coping Strategies}

Overall, participants showed a great deal of resilience and resourcefulness in coping with challenges that come with experiencing mental health issues. Accessing campus resources and making regular visits to a counsellor were seen as major coping strategies. Campus counsellors helped stressed students to learn useful skills, such as breathing exercises, and helped them to put things into perspective. The most important part for participants was simply having someone to talk to. One participant noted:

I think the most effective strategy when dealing with stress is to talk to someone, especially people that you trust, you are close with ... If you don't have a family member or friends ... I would really suggest that you go see a counsellor. They are really helpful; they don't intimate [sic] you at all ... They are not really telling you what to do, they are like a guide. ( $\mathrm{S} 1 \mathrm{P} 1)$

Other strategies included ways of keeping organized, such as using lists and an agenda to keep track of tasks and remain aware of upcoming deadlines. In one case, engaging in a temporary distraction, such as watching television, proved effective: "It is nice to take a little break, comedic break, and kind of forget about what you are stressing about and remember that it's probably not as important as you think it is" ( $\left.\mathrm{S}_{1} \mathrm{P} 2\right)$. Another participant mentioned that social networks were important for mental health: "I am a very social person. I need to see people, even if it is seeing my friend after class ... It is important for me to have those kinds of moments." (S4P6)

One participant pointed out that physical well-being, sustained by regular exercise, can help a person cope with the stress that comes with studying and mental health issues: "I'm finding physical activity does help out quite a lot with reducing stress and tension" (S4P1). Another used meditation: "Meditation really helps, kind of concentrating your energy, you just focus and breathe and shut your eyes for just a few seconds" (S1P3). A 
combination of various techniques was suggested to reduce stress: "Exercising more . . . having a better well-rounded diet, and joining a club on campus . . . I also incorporate some kind of mindfulness or calming strategies" (S2P4).

\section{The Final Documentary}

The final documentary included a three-minute introductory clip, five three-minute clips to represent each theme, and a three-minute commentary clip reflecting the experiences of the lead co-investigators on the project.

\section{Discussion}

This qualitative study used a videovoice method to investigate the culture in postsecondary campuses with respect to mental health problems in the student body, and to inquire into the coping strategies used by students facing mental stress. The videovoice method enabled and empowered participants (students and staff) to convey their opinions and thoughts about mental health on campus in real time, allowing the researcher to probe for qualitative information after each question. Videovoice, as a process of empowerment and resilience building, was particularly straightforward from the community members compared to the paper chase that would be occasioned by the collection of information from school administrators. Our final documentary has been uploaded to a videosharing website for public viewing. The lead co-investigators were encouraged to use the documentary to promote mental health at their local campus. Overall, the student researchers were excited to have a unique opportunity to contribute to this important research topic, and they were encouraged by the diversity of ideas and experiences they shared with the other participants.

Five themes emerged in our investigation: the stigma of mental illness, campus culture related to mental health, mental health services available and barriers to mental health services on campus, campus accommodations for students' mental health needs, and student mental health coping strategies.

The study investigated the public stigma (the negative stereotypes and prejudice about mental illness held collectively by people in a society or a community) and the self-stigma (identifying the self with the stigmatized group and internalizing public stigma) associated with mental health problems (Corrigan, 2004; Corrigan, Kerr, \& Knudsen, 2005). A qualitative analysis yielded the following aspects. Participants expressed that while many professors can be supportive, there is a presence of stigma on the behalf of their peers as a form of public stigma. International students reported feeling particularly uncomfortable when seeking help and had a tendency to identify themselves with a stigmatized group, applying to themselves the stereotypes and prejudices innate in public stigma (Hunt \& Eisenberg, 2010). Participants in the current study reported that stigma does not vanish during counselling; however, the comfort established with counselling was helpful for some individuals. Interestingly, a related study conducted by Sibicky and Dovidio (1986) explained that individuals using counselling services were perceived negatively compared to individuals who did not receive counselling. In other words, counselling service users might be stigmatized during their quest for recovery.

Peers and peer pressure were described by participants in the current study as sources of stigma; however, some participants identified peers as important sources of aid and 
support. Consistent with this view, previous research found that supportive peers can enhance people's mental health (Anthony, 1993; Davidson, 1999). We also heard that being labelled with a mental illness, and being treated "differently" by teachers and staff, can rupture friendships. Therefore, an unwillingness to speak openly about problems with one's personal mental health can arise from underlying fears of isolation, discrimination, and devaluation (Moses, 2010).

The lack of awareness surrounding mental illness has called for an increase in mental health support initiatives to correct negative perceptions of mental illness and, more importantly, to provide services to treat mental illness. It is well established that universities are not ignorant of mental health problems among their students, and many student associations execute a variety of projects to promote mental health on campus. However, according to our findings in this project, resources are still insufficient, whether the resources in question are financial (lack of funds to invest in projects) or human (lack of counsellors or psychologists). While available services exist, they are not promoted efficiently and openly, and accessibility to these services needs to be improved. For example, participants mentioned that campus mental health services provide few compatible timeslots or have long wait lists. The stigma attached to mental illness, and even to mental stress, is probably to blame for the dearth of attention this problem receives on campuses.

CACUSS and the Canadian Mental Health Association (2013) have emphasized that improvement in mental health service accessibility leads to greater retention of postsecondary students. Certain actions (beyond funding) can be implemented to improve counselling, such as focusing on strength and recovery, peer counselling, offering individual and group therapy, and a streamlined referral process to other academic services or to local hospitals. Students have come to realize that the structure of the system is aimed toward short-term support instead of long-term therapy. A student can be accommodated for a mental health need if the student is diagnosed with a mental disability. However, the student must be knowledgeable about where to go to get such services. In the present study, many participants felt that even though they had psychosocial or emotional issues, their demands would not be taken seriously without a psychiatric or psychological diagnosis. Therefore, a more proactive stance by campus mental health services is warranted.

Fortunately, when dealing with overwhelming stress, students use different strategies to cope. They have intrinsic motivation to seek out help to extinguish discomfort. In the present study, participants reported that they tended to use social means, as well as engage in both active and passive activities, such as discussion with friends, exercise, or relaxation.

\section{Study Limitations}

The interviewers did not use a standardized set of questions to guide the interviews. This could be regarded as a strength as well as a limitation. It allowed us to collect a variety of qualitative data. However, the data were not necessarily consistent for all participants.

The majority of participants were women. Thus, the male point of view on these topics is under-represented in this study. This is consistent with the findings of other researchers who testify that men are difficult to engage in mental health and wellness strategies (Rickwood, Deane, Wilson, \& Ciarrochi, 2005). 


\section{Conclusion}

The study provided a unique insight into campus culture related to mental health and found that stigma is still attached to students who present mental health problems. Although there are many opportunities to improve mental health services at postsecondary institutions in Canada-such as the promotion of mental health services, accommodations for students with mild mental health issues, and referrals for students with more severe mental problems-insufficient funding is applied to support mental health infrastructure. We have demonstrated that students are willing and ready to become part of the conversation. The results that were reported by participants can be extracted to develop quantitative survey tools and to build a comprehensive strategy to combat stigma as well as to improve mental health services on campus for all postsecondary students in Canada.

\section{Acknowledgements}

Funds were provided for this project from Jack.org, Queen's University's Bell Canada Mental Health and Anti-Stigma Research Chair, and the Mental Health Commission of Canada's Opening Minds anti-stigma initiative, which is funded through Health Canada.

\section{References}

Adlaf, E., Demers, A., \& Gliksman, L. (2005). Canadian Campus Survey 2004. Retrieved from https://www.camh.ca/en/research/research_areas/institute-mh-policyresearch/Documents/CCS_2004_report.pdf

American College Health Association-National College Health Assessment (ACHANCHA) II (2009). Ontario Reference Group executive summary. Retrieved from http:// www.ryerson.ca/content/dam/healthandwellness/healthpromotion/forms/NCHAII\%20WEB\%20SPRING\%202009\%20ONTARIO\%20REFGRP\%20EXECUTIVE\%20 SUMMARY.pdf

Anthony, W. (1993). Recovery from mental illness: The guiding vision of the mental health service system in the 1990s. Psychosocial Rehabilitation Journal, 16(4), 11-23. doi:10.1037/hoo95655

Bray, S., \& Born, H. (2004). Transition to university and vigorous physical activity: Implications for health and psychological well-being. Journal of American College Health, 52(4), 181-188.

Canadian Association of College and University Student Services \& Canadian Mental Health Association. (2013). Post-secondary student mental health: Guide to a systemic approach. Vancouver, BC: Authors. Retrieved from http://www.cacuss.ca/_Library/ PSSMH/PSSMH_GuideToSystemicApproach_CACUSS-CMHA_2013.pdf

Catalani, C., Veneziale, A., Campbell, R. L., Herbst, S., Butler, B., Springgate, B., \& Minkler, M. (2012). Videovoice: Community assessment in post-Katrina New Orleans. Health Promotion Practice, 13(1), 18-28.

Centre for Addition and Mental Health (CAMH). (n.d.). Theory, definitions and context for mental health promotion. Retrieved from http://www.camh.ca/en/hospital/ about_camh/health_promotion/the_yale_new_haven_primary_prevention_program/ Pages/theory_def_context.aspx\#mhpromotion 
Corrigan, P., Markowitz, F. E., Watson, A., Rowan, D., \& Kubiak, M. A. (2003). An attribution model of public discrimination towards persons with mental illness. Journal of Health and Social Behavior, 44(2), 162-179.

Corrigan, P. W. (2004). How stigma interferes with mental health care. American Psychologist, 59(7), 614-625.

Corrigan, P. W., Edwards, A. B., Green, A., Diwan, S. L., \& Penn, D. L. (2001). Prejudice, social distance, and familiarity with mental illness. Schizophrenia Bulletin, 27(2), 219-225.

Corrigan, P. W., Kerr, A., \& Knudsen, L. (2005). The stigma of mental illness: Explanatory models and methods for change. Applied and Preventive Psychology, 11(3), 179-190.

Davidson, L. (1999). Peer support among individuals with severe mental illness: A review of the evidence. Clinical Psychology: Science and Practice, 6(2), 165-187. doi:10.1093/clipsy.6.2.165

Eisenberg, D., Downs, M. F., Golberstein, E., \& Zivin, K. (2009). Stigma and help seeking for mental health among college students. Medical Care Research and Review, 66(5), 522-541.

Gubrium, A. C., \& Turner, N. (2011). Digital storytelling as an emergent method for social research and practice. In S. N. Hesse-Biber (Ed.), Handbook of emergent technologies in social research (pp. 469-491). New York, NY: Oxford University Press.

Heck, E., Jaworska, N., DeSomma, E., Dhoopar, A. S., MacMaster, F. P., Dewey, D., \& MacQueen, G. (2014). A survey of mental health services at post-secondary institutions in Alberta. Canadian Journal of Psychiatry, 59(5), 250-258.

Hunt, J., \& Eisenberg, D. (2010). Mental health problems and help-seeking behavior among college students. Journal of Adolescent Health, 46(1), 3-10. DOI:10.1016/j. jadohealth.2009.08.008.

Jack.org. (2013). Student Summit. Retrieved from https://www.jack.org/summit

Lunch, N., \& Lunch, C. (2006). Insights into participatory video: A handbook for the field. Oxford, UK: InsightShare.

Mahmoud, J., Staten, R., Hall, L., \& Lennie, T. (2012). The relationship among young adult college students' depression, anxiety, stress, demographics, life satisfaction, and coping styles. Issues in Mental Health Nursing, 33(3), 149-156. doi:10.3109/01612840. 2011.632708

Moses, T. (2010). Being treated differently: Stigma experiences with family, peers, and school staff among adolescents with mental health disorders. Social Science \& Medicine, 7O(7), 985-993. doi:10.1016/j.socscimed.2009.12.022

Mowbray, C. T., Megivern, D., Mandiberg, J. M., Strauss, S., Stein, C. H., Collins, K., Kopels, S., . . Lett, R. (2006). Campus mental health services: Recommendations for change. American Journal of Orthopsychiatry, 76(2), 226-237.

Perez, R. N., Murphy, S., \& Gill, M. (2014). Policy paper: Student health and wellness. Retrieved from http://www.ousa.ca/wordpress/wp-content/uploads/2014/11/StudentHealth-and-Wellness-2014.pdf 
Rickwood, D., Deane, F. P., Wilson, C. J., \& Ciarrochi, J. (2005). Young people's helpseeking for mental health problems. Australian e-Journal for the Advancement of Mental Health, 4(3), 218-251.

Sibicky, M., \& Dovidio, J. (1986). Stigma of psychological therapy: Stereotypes, interpersonal reactions, and the self-fulfilling prophecy. Journal of Counseling Psychology, 33(2), 148-154. doi:10.1037/0022-0167.33.2.148

Statistics Canada. (2011). Leading causes of death, total population, by age group and sex, Canada. Retrieved from http://www5.statcan.gc.ca/cansim/ a26?lang=eng\&id $=1020561$

Terenzini, P., Rendon, L., Upcraft, M., Millar, S., Allison, K., Gregg, P. L., \& Jalomo, R. (1994). The transition to college: Diverse students, diverse stories. Research in Higher Education, 35(1), 57-74.

Wang, C., \& Burris, M. A. (1997). Photovoice: Concept, methodology, and use for participatory needs assessment. Health Education \& Behavior, 24(3), 369-387.

Warren, C. M., Knight, R., Holl, J. L., \& Gupta, R. S. (2014). Using videovoice methods to enhance community outreach and engagement for the national children's study. Health Promotion Practice, 15(3), 383-394. doi:10.1177/1524839913503470

Wexler, L., Gubrium, A., Griffin, M., \& DiFulvio, G. (2013). Promoting positive youth development and highlighting reasons for living in northwest Alaska through digital storytelling. Health Promotion Practice, 14(4), 617-623.

\section{Contact Information}

\section{Shu-Ping Chen}

Department of Occupational Therapy

Faculty of Rehabilitation Medicine

University of Alberta, Edmonton, AB

shuping2@ualberta.ca

Dimitris Giamos is an honors undergraduate psychology student at Concordia University and a mental health advocate. He is interested in mental health stigma and its implications for young adults. Currently, he is conducting research on auditory-motor synchronization in the Penhune Laboratory of Motor Learning and Neural Plasticity, Montreal, Quebec.

Alex Young Soo Lee is a graduate from the Bachelor of Health Sciences Program at McMaster University. He has led a number of mental health research initiatives at a municipal level and is continuously doing research in the field of mental health and addictions. His research interest is focused on neuropsychological correlates of episodic simulation of future events in patients with depression, adolescent bereavement, and genetic links to mental health and addictions.

Amanda Suleiman is a Master of Social Work candidate at McMaster University and a mental health advocate. Her research and practice interests involve young people and mental health, particularly within schools and postsecondary settings. More specifically, 
her MSW thesis focused on the experiences of social work students who experience mental health disabilities and/or Madness.

Heather Stuart is a full professor in the Departments of Public Health Sciences and Psychiatry and the School of Rehabilitation Therapy at Queen's University. She holds the Bell Canada Mental Health and Anti-Stigma Research Chair at Queen's University. Dr. Stuart is also the Senior Consultant to the Mental Health Commission of Canada's Opening Minds anti-stigma initiative and the past Chair of the World Psychiatric Association's Stigma and Mental Health Scientific Section. Dr. Stuart's research focuses on mental health services evaluation, with a specific focus on the destigmatization of mental illnesses.

Shu-Ping Chen is an assistant professor in the Department of Occupational Therapy at the University of Alberta. Dr. Chen's teaching and research focuses on people with mental health issues, including two main themes: social inclusion for individuals with mental illnesses and mental health promotion. She has expertise in research related to stigma reduction, recovery, and substance misuse. Her current project aims at reducing the stigma associated with substance misuse and creating a more inclusive postsecondary campus environment. 